\title{
A produção acadêmica sobre trabalho docente na educação básica no Brasil: 1987-2007
}

\section{The academic production on teachers' work in Brazilian basic education: 1987-2007}

\author{
Adriana Duarte ${ }^{1}$
}

\begin{abstract}
RESUMO
Este artigo apresenta estudo quantitativo concernente às produções acadêmicas (dissertações e teses) sobre o trabalho docente na educação básica no período de 1987 a 2007. A fonte básica utilizada para levantamento dos trabalhos foi o "Banco de Dissertações e Teses da Coordenação de Aperfeiçoamento de Pessoal de Nível Superior - CAPES” e a busca se deu por meio de sete descritores, derivados da categoria principal "trabalho docente". Os resultados deste estudo mostram o conjunto de trabalhos produzidos, a ordenação por períodos históricos, os principais aspectos investigados, a difusão de subtemas ao longo do tempo, os níveis e as etapas da educação pesquisados e os locais de produção. Trata-se de um trabalho de sistematização dos dados encontrados e de proposição de hipóteses de investigação para posterior elaboração do estado da arte.

Palavras-chave: trabalho docente; educação básica; produção acadêmica.
\end{abstract}

\begin{abstract}
This paper presents a quantitative study concerning academic productions (dissertations and theses) on teachers' work in basic education from 1987 to 2007. The basic source used for research was "CAPES", a Brazilian Bank of Dissertations and Theses, and it was carried out through seven descriptors, derived from the main category "faculty work." The results of

1 Doutora em Educação. Professora da Faculdade de Educação - FAE - da Universidade Federal de Minas Gerais - UFMG. Vice-coordenadora do Grupo de Pesquisa sobre Política Educacional e Trabalho Docente: GESTRADO/FAE/UFMG, Brasil. E-mail: dri-duarte@uol.com.br
\end{abstract}


this study show the group of works produced, their ordering in historical periods, the main investigated aspects, the diffusion of subthemes throughout time, the researched levels and stages of education, and the locations of production. This is a work for systematization of found data and proposition of investigation hypotheses for further elaboration on the state of the art. Keywords: teachers' work; basic education; academic production.

Este artigo originou-se da pesquisa "Trabalho Docente na Educação Básica no Brasil"', que, na sua meta dois, prevê a revisão de literatura acadêmica sobre a temática do trabalho docente. $\mathrm{O}$ estudo ${ }^{3}$ quantitativo elaborado aqui foi construído por meio dos resultados da primeira etapa dessa revisão, que incluiu o levantamento de teses e dissertações defendidas sobre o trabalho docente, no período de 1987 a 2007. O mapeamento realizado abrange a análise da produção discente de 65 programas de pós-graduação de instituições públicas e privadas, catalogadas no banco de dissertações e teses da Coordenação de Aperfeiçoamento de Pessoal de Nível Superior (Capes).

O objetivo deste estudo é sistematizar a produção acadêmica sobre o trabalho docente na educação básica no Brasil, a fim de verificar o conjunto de informações e resultados já obtidos. Ou seja, inventariar o conjunto de trabalhos produzidos, ordená-los por períodos históricos, situar os principais aspectos investigados e os locais de produção, enfim, indicar alguns caminhos, escolhas e dimensões que esses estudos vêm tomando e que possam contribuir no fortalecimento desse campo de investigação.

A fonte básica de referência para localizar os trabalhos, conforme indicado anteriormente, foi o "Banco de Dissertações e Teses da Capes". O "trabalho docente" foi o nosso descritor de referência ${ }^{4}$ para arrolamento das produções

2 Projeto sob a coordenação geral das professoras Dalila Andrade Oliveira e Lívia Maria Fraga Vieira, ambas da FAE/UFMG e realizado por meio de "Convênio de Cooperação Técnica entre MEC/Secretaria de Educação Básica e UFMG/Faculdade de Educação". Este projeto está sendo desenvolvido simultaneamente em sete Estados brasileiros (RN, PA, GO, MG, ES, PR, SC), envolvendo oito grupos de pesquisas de universidades públicas (UFRN, UFPA, UFGO, UFMG, UFES, UFPR, UEM, UFSC).

3 Este estudo contou com a colaboração dos estudantes de iniciação científica: Lídia Campos Gomes Boy (FAPEMIG), Magna Patrícia de Paula (Fundep/Santander) e Arituza Ferreira de Jesus $(\mathrm{CNPq})$, na busca de dados nos acervos bibliográficos. Contou, ainda, com a contribuição do mestrando Tiago Jorge na elaboração de tabelas e gráficos, por meio do instrumento SPSS.

4 Não foram utilizados neste estudo os descritores definidos pela Biblioteca Virtual de Educação - BVE, considerando que o banco de dissertações e teses da Capes não usa esses descritores como critério de arquivamento dos trabalhos. Argumenta-se, ainda, não ser tradição dos pesquisadores da área de educação eleger esses descritores em seus estudos de estado da arte, conforme demonstram pesquisas realizadas por André et al. (1999), Ferreira (1999; 2002), Brzezinski e Garrido (1999), Soares e Maciel (2000); Brzezinski (2007), entre outros. 
acadêmicas. Para cercar, nesse levantamento trabalhos similares, optou-se por desdobrar esse descritor em expressões e termos sinônimos, mais usualmente utilizados em artigos acadêmicos publicados sobre o trabalho docente, como: profissão docente, profissão de professor, atividade docente, carreira docente, ofício de professor, condição docente e magistério. A busca dos trabalhos se deu por meio da ferramenta "expressão exata", contida no site da Capes, que possibilita localizar de forma precisa as expressões e os termos indicados.

A procura minuciosa dos descritores foi dirigida aos títulos e às palavras-chave indicadas pelos autores nas dissertações e nas teses. Partiu-se do pressuposto de que os autores se esforçam para registrar nesses lugares os aspectos centrais das temáticas desenvolvidas por eles. Ou seja, espera-se que nesses itens apareçam aspectos que possam indicar o principal conteúdo da investigação, o que nem sempre se verificou.

Foram encontrados 467 trabalhos, sendo 388 dissertações e 79 teses, que abrangeram o período de 1987 - data do mais antigo trabalho arquivado no banco de dados da Capes - a 2007; esta última é a data do último trabalho disponível, no decorrer da coleta de dados. Esse período, que compreende vinte anos de produção acadêmica, abrange a Constituinte (1987), a promulgação da Constituição de 1988, a Lei de Diretrizes e Bases da Educação Nacional (1996) e uma série de outras leis as quais se destinam a matérias específicas sobre a educação e que, no seu conjunto, conformaram as reformas pelas quais passaram a educação brasileira nos anos 1990 e 2000 . Adotando como referência esses marcos históricos, os trabalhos encontrados foram organizados em dois períodos: o primeiro de 1987 a 1996, que demarca a Constituinte (1987); a Promulgação da Constituição (1988); e a promulgação da LDBEN (1996); e o segundo entre 1997 e 2008, período que delimita a implementação da LDBEN e todas as suas alterações até 2007.

Os dados coletados em cada dissertação e tese foram: título, autoria, orientador, tipo (mestrado ou doutorado), instituição, data de defesa, palavras-chave e resumo. O banco de teses e dissertações da Capes é organizado para que os dados acima estejam disponíveis; no entanto, nem todos os trabalhos catalogados apresentam esses itens por completo. Os resumos disponíveis são os elaborados pelo(a) autor(a) do trabalho, indicando não haver, ou não ser cumprida, uma padronização para a sua apresentação.

Desta forma, os resumos dos trabalhos se apresentam de tamanhos diferentes, completos, incompletos, com recortes de trechos da introdução e, às vezes, com redações incompreensíveis. Mesmo com todas as limitações já identificadas por outros autores ${ }^{5}$ para se realizar pesquisas sobre o estado da arte via resumos, há o reconhecimento de que eles podem oferecer uma história da

5 Ver Ferreira (2002) e Stephanou (2008). 
produção acadêmica e formam "um horizonte rico para compreender as opções, direções, escolhas e desatenções que temos produzido no campo da pesquisa na pós-graduação em Educação" (STEPHANOU, 2008, p. 22).

As 467 dissertações e teses encontradas foram organizadas em eixos temáticos, que agruparam, pelo objeto focalizado, os trabalhos que mais se aproximavam. Nesse sentido, buscou-se reunir trabalhos similares, por meio das informações oferecidas pelos autores nos resumos apresentados, ainda que eles adotassem objetivos e abordagens teórico-metodológicas distintas. Aliado a esse, tomou-se também como critério a recorrência com que esses trabalhos apareciam, ou seja, tópicos que se apresentavam com mais frequência e que revelavam um grau de distinção em relação aos outros e mereciam estar destacados.

Assim, chegou-se a treze eixos temáticos, quais sejam: 1. Natureza e Processo de Trabalho; 2. Condições e Relações de Trabalho; 3. Identidade e Trabalho Docente; 4. Representações, Sentidos e Significados sobre o Trabalho Docente; 5. Perfil de Professor; 6. Gênero e Trabalho Docente; 7. Formação Docente; 8. Novas Tecnologias e Trabalho Docente; 9. Saúde e Mal-Estar Docente; 10. Saber e Práticas Docentes; 11. Aspectos Teórico- Históricos do Trabalho Docente; 12. Impactos das Reformas Educacionais sobre o Trabalho Docente; 13. Sindicalismo/Resistência e Trabalho Docente.

Na seção seguinte, são apresentadas as primeiras sínteses dos dados coletados, que buscaram ordenar os trabalhos encontrados por períodos de crescimento dessa temática ao longo do tempo, os locais de produção, os níveis e as etapas da educação pesquisados, a difusão de subtemas estudados ao longo do tempo. Para finalizar, são mostradas algumas indicações possíveis de se vislumbrar para a análise qualitativa dos estudos produzidos nessa área do conhecimento.

\section{O que anuncia a produção acadêmica?}

A categoria central de análise no projeto que originou este estudo é o trabalho docente, sendo entendido de forma mais ampla. Vejamos:

Compreende não só o trabalho realizado em sala de aula, como o processo que envolve o ensino e a aprendizagem, mas, também, a participação do professor no planejamento das atividades, na elaboração de propostas político-pedagógicas e na própria gestão da escola, incluindo formas coletivas de realização do trabalho escolar e articulação da escola com as famílias e a comunidade (DUARTE et al., 2008, p. 222). 
O trabalho docente é concebido nesse projeto como parte da totalidade constituída pelo trabalho no capitalismo, estando submetido, portanto, à sua lógica e às suas contradições. A sociedade capitalista é recortada por múltiplas dinâmicas específicas da organização produtiva, do sistema político e social, do conhecimento, da tecnologia, de gênero etc. Nessa perspectiva, constroem-se as dinâmicas sociais, que são as formas de organização social, as estruturas particulares de processos mais gerais. Muitas dessas dinâmicas se entrecruzam no espaço escolar (BIRGIN, 2000).

Nesse sentido, a categoria "trabalho docente" abarca tanto os sujeitos nas suas complexas definição, experiência e identidade, quanto as condições em que as atividades são realizadas no contexto escolar. Compreende, portanto, as atividades, responsabilidades e relações que se realizam na escola, para além da regência de classe.

O mapeamento das dissertações e das teses, por meio do descritor principal "trabalho docente", apresentado na Tabela 1, revelou-nos que essa expressão aparece nas palavras-chave e/ou nos títulos de 38\% dos trabalhos encontrados, seguidos dos descritores "magistério", com 31\%, e "profissão docente" com $12 \%$. Esses três descritores reúnem $81 \%$ das produções. Chama a atenção também nesse levantamento o número ínfimo de trabalhos encontrados com os descritores "ofício de professor" (1) e "condição docente" (3), que pode estar indicando um certo silenciamento dessas categorias nas investigações sobre o trabalho docente (Tabela 1).

TABELA 1 - TESES E DISSERTAÇÕES PRODUZIDAS SOBRE TRABALHO DOCENTE POR DESCRITOR - 1987-2007

\begin{tabular}{l|c|c|c|c|c}
\hline \multirow{2}{*}{ Descritor } & \multicolumn{4}{|c|}{ Período } & \multirow{2}{*}{ Total } \\
\cline { 2 - 5 } & \multicolumn{2}{|c|}{$\mathbf{1 9 8 7 - 1 9 9 6}$} & \multicolumn{2}{c}{$\mathbf{1 9 9 7 - 2 0 0 7}$} & \\
\hline Atividade docente & Quant. & $\%$ & Quant. & $\%$ & \\
Carreira docente & 2 & 10,0 & 18 & 90,0 & 20 \\
Condição docente & 0 & - & 11 & 100,0 & 11 \\
Magistério & 1 & 33,3 & 2 & 66,7 & 3 \\
Ofício de professor & 61 & 41,5 & 86 & 58,5 & 147 \\
Profissão de professor & 0 & - & 1 & 100,0 & 1 \\
Profissão docente & 6 & 33,3 & 12 & 66,7 & 18 \\
Trabalho de professor & 3 & 5,6 & 51 & 94,4 & 54 \\
Trabalho docente & 2 & 6,1 & 31 & 93,9 & 33 \\
Total & 34 & 19,0 & 145 & 81,0 & 179 \\
\hline
\end{tabular}

FONTE: Banco de dissertações e teses da Capes. 
Verifica-se na Tabela 2 que as dissertações e as teses reunidas no descritor "Trabalho Docente" se concentram prioritariamente na discussão de temáticas referentes ao eixo "Formação Docente". Nesse eixo, convergiram, principalmente, trabalhos sobre formação e profissionalização docente; formação inicial de professores no ensino médio e na educação superior relacionando-a com as atividades docentes na educação básica (educação infantil, ensino fundamental e médio); formação continuada e em serviço de professores e as exigências da atividade docente; formação e atividade docente no início da carreira do professor; formação docente e desvalorização do professor; tendências pedagógicas e práticas docentes.

As problematizações de aspectos relativos à "Natureza do Trabalho Docente" (24), "Processo de Trabalho e Condições de Trabalho" (15), nas teses e dissertações encontradas (Tabela 2), expressaram-se em investigações relativas aos determinantes políticos da profissão de professor; sobre as configurações do trabalho docente na atualidade; a proletarização e profissionalização docente; a questão do trabalho produtivo ou improdutivo na organização escolar; nas mudanças na organização do trabalho na escola e os reflexos sobre o trabalho do professor; na intensificação, flexibilização e precarização do trabalho docente; políticas de valorização do magistério e condições de trabalho docente; abandono da profissão docente dos professores das redes públicas. Essas produções reuniram $22 \%$ dos trabalhos localizados com o descritor "Trabalho Docente". Os trabalhos que estudaram a "Saúde e Mal-Estar Docente" (15) versavam principalmente sobre as causas mais frequentes do adoecimento dos docentes, entre elas a síndrome de Burnout; prevalência de problemas vocais e estresse em professores; condições de vida e trabalho e as consequências sobre a saúde mental do professor; implicações do tempo na saúde e no trabalho docente.

Já o descritor "Magistério" teve 20\% dos trabalhos encontrados (Tabela 2) classificados no eixo "Gênero e Trabalho Docente", que agrupou estudos sobre feminização do magistério; expressão das relações sociais de gênero no interior do magistério; relações de gênero nas práticas docentes de professores dos anos iniciais; processos identitários na constituição profissional de professores do gênero masculino que atuam nas séries iniciais e educação infantil; experiências de homens que fizeram carreira no magistério público. Chama a nossa atenção que esse descritor acumulou o maior número de trabalhos relativos aos eixos "Impacto das Reformas Educacionais sobre o Trabalho Docente" (32) e "Sindicalismo, Resistência e Trabalho Docente" (18), se comparado com os estudos coletados com o descritor "Trabalho Docente", que não registrou nenhuma dissertação e tese classificada neste último eixo (Tabela 2).

Os estudos voltados para o impacto das reformas educacionais sobre o trabalho docente (32) abarcam desde uma discussão da concepção de trabalho docente ante as mudanças que vem sofrendo essa profissão até a compreensão das interferências das reformas nas relações de trabalho desses profissionais; no processo de trabalho 
na escola; nas normas que determinam a carreira e a remuneração e na autonomia dos professores (Tabela 2).

De forma geral, as dissertações e teses desenvolvidas sobre o trabalho docente, no período estudado, têm buscado focar os processos de formação e de profissionalização, o exercício da docência, a construção da identidade docente, os processos de trabalho, as condições e as relações de trabalho, o processo de resistência, bem como o de abandono e o adoecimento dos profissionais da docência. Portanto, o trabalho docente é estudado em suas múltiplas variantes, apresentando conceitos e referenciais que devem ser compreendidos nas especificidades dos posicionamentos teóricos dos autores ou grupos de pesquisas que estão envolvidos.

TABELA 2 - TESES E DISSERTAÇÕES SOBRE O TRABALHO DOCENTE POR DESCRITOR E EIXO TEMÁTICO

\begin{tabular}{|c|c|c|c|c|c|c|c|}
\hline \multirow{3}{*}{ Eixos temáticos } & \multicolumn{7}{|c|}{ Descritor } \\
\hline & \multicolumn{2}{|c|}{ Magistério } & \multicolumn{2}{|c|}{$\begin{array}{c}\text { Profissão } \\
\text { docente }\end{array}$} & \multicolumn{2}{|c|}{$\begin{array}{c}\text { Trabalho } \\
\text { docente }\end{array}$} & \multirow[t]{2}{*}{ Total } \\
\hline & Quant. & $\%$ & Quant. & $\%$ & Quant. & $\%$ & \\
\hline $\begin{array}{l}\text { Aspectos teórico- } \\
\text { históricos sobre o trabalho } \\
\text { docente }\end{array}$ & 6 & 20,7 & 10 & 34,5 & 13 & 44,8 & 29 \\
\hline $\begin{array}{l}\text { Condições/relações de } \\
\text { trabalho docente }\end{array}$ & 13 & 35,1 & 9 & 24,3 & 15 & 40,5 & 37 \\
\hline Formação docente & 14 & 17,8 & 4 & 4,9 & 63 & 77,8 & 81 \\
\hline Gênero e trabalho docente & 30 & 76,9 & 3 & 7,7 & 6 & 15,4 & 39 \\
\hline $\begin{array}{l}\text { Identidade e trabalho } \\
\text { docente }\end{array}$ & 6 & 28,6 & 10 & 47,6 & 5 & 23,8 & 21 \\
\hline $\begin{array}{l}\text { Impacto das reformas } \\
\text { sobre o trabalho docente }\end{array}$ & 32 & 62,7 & 3 & 5,9 & 16 & 31,4 & 51 \\
\hline $\begin{array}{l}\text { Mal-estar docente e saúde } \\
\text { do professor }\end{array}$ & 1 & 5,9 & 1 & 5,9 & 15 & 88,2 & 17 \\
\hline $\begin{array}{l}\text { Natureza e processo de } \\
\text { trabalho docente }\end{array}$ & 2 & 7,1 & 2 & 7,1 & 24 & 85,7 & 28 \\
\hline $\begin{array}{l}\text { Novas tecnologias e } \\
\text { trabalho docente }\end{array}$ & 3 & 37,5 & 0 & - & 5 & 62,5 & 8 \\
\hline Perfil de professores & 5 & 62,5 & 3 & 37,5 & 0 & - & 8 \\
\hline $\begin{array}{l}\text { Práticas educativas e } \\
\text { saberes docentes }\end{array}$ & 2 & 22,2 & 0 & - & 7 & 77,8 & 9 \\
\hline $\begin{array}{l}\text { Sindicalismo-resistência e } \\
\text { trabalho docente }\end{array}$ & 18 & 90,0 & 2 & 10,0 & 0 & - & 20 \\
\hline $\begin{array}{l}\text { Representações, sentidos e } \\
\text { significados }\end{array}$ & 15 & 46,9 & 7 & 21,9 & 10 & 31,3 & 32 \\
\hline Total & 147 & 38,7 & 54 & 14,2 & 179 & 47,0 & 380 \\
\hline
\end{tabular}

FONTE: Banco de dissertações e teses da Capes. 
No que se refere às etapas e modalidades da educação básica verifica-se que o ensino fundamental foi a etapa que mais concentrou os estudos sobre o trabalho docente, com 145 trabalhos (Tabela 3), 31\% das dissertações e das teses, seguidas do ensino médio regular e profissionalizante, que, juntos, somam 90 trabalhos, ou seja, 19\% da produção. Aparecem, em número bem menor, estudos que analisam simultaneamente o trabalho docente em mais de uma etapa da educação básica, como o ensino fundamental e o médio, que reuniu $4 \%$ da produção. Os trabalhos relativos à educação infantil somam $3 \%$ da produção total. É importante registrar que a maioria dos resumos analisados (35\%) não registrou a(s) etapa(s) da educação básica ou a modalidade de educação a que seus estudos se referem. Alguns autores(as), isto é, 7\%, anotam genericamente que seu trabalho está voltado para investigar a educação básica, sem localizar a etapa ou a modalidade (Tabela 3).

TABELA 3 - TESES E DISSERTAÇÕES PRODUZIDAS SOBRE TRABALHO DOCENTE POR ETAPA E MODALIDADES DA EDUCAÇÃO BÁSICA - 1987-2007

\begin{tabular}{|c|c|c|c|c|c|}
\hline \multirow{3}{*}{$\begin{array}{l}\text { Etapas da educação } \\
\text { básica e modalidades } \\
\text { de educação }\end{array}$} & \multicolumn{4}{|c|}{ Período } & \multirow{3}{*}{ Total } \\
\hline & \multicolumn{2}{|c|}{ 1987-1996 } & \multicolumn{2}{|c|}{ 1997-2007 } & \\
\hline & Quant. & $\%$ & Quant. & $\%$ & \\
\hline Educação básica & 3 & 9,4 & 30 & 90,6 & 33 \\
\hline Ensino fundamental & 22 & 15,2 & 123 & 84,8 & 145 \\
\hline Ensino médio & 11 & 22,0 & 39 & 78,0 & 50 \\
\hline $\begin{array}{l}\text { Ensino médio profis- } \\
\text { sionalizante }\end{array}$ & 20 & 50,0 & 20 & 50,0 & 40 \\
\hline Educação infantil & 1 & 8,3 & 11 & 91,7 & 12 \\
\hline $\begin{array}{l}\text { Educação infantil e } \\
\text { ensino fundamental }\end{array}$ & 2 & 100,0 & 0 & - & 2 \\
\hline $\begin{array}{l}\text { Ensino fundamental e } \\
\text { médio }\end{array}$ & 2 & 10,5 & 17 & 89,5 & 19 \\
\hline EJA & 0 & - & 3 & 100,0 & 3 \\
\hline Não informado & 48 & 29,4 & 115 & 70,6 & 163 \\
\hline Total & 109 & 23,3 & 358 & 76,7 & 467 \\
\hline
\end{tabular}

FONTE: Banco de dissertações e teses da Capes.

Ao cotejarmos os subtemas presentes, por etapa ou modalidade de ensino, podemos constatar que no ensino fundamental destaca-se a produção nos seguintes eixos temáticos: Formação Docente (17\%); Impacto das Reformas Educacionais no Trabalho Docente (15\%); Condições e Relações de Trabalho (10\%); Natureza e Processo de Trabalho (10\%); Representações, Sentidos e Significados (9,5\%). Este último eixo reuniu trabalhos que versam sobre as representações dos meios 
de comunicação sobre a profissão do professor; as representações que os docentes do ensino fundamental constroem sobre o seu ofício; as representações sociais sobre o início da carreira de professor; os significados atribuídos pelos professores à desvalorização profissional e ao abandono da carreira do magistério.

No ensino médio regular e profissionalizante, o grosso da produção está focado no eixo Formação Docente, que aglutinou 58 trabalhos, ou seja, 64\% da produção. Na Educação Infantil os 12 trabalhos encontrados estão mais distribuídos entre os eixos, mas se pode destacar dois deles: Formação Docente (33\%) e Gênero e Trabalho Docente, também com 33\% dos trabalhos (Tabela 4).

TABELA 4 - DISSERTAÇÕES E TESES PRODUZIDAS POR EIXO TEMÁTICO EM CADA ETAPA DA EDUCAÇÃO BÁSICA

\begin{tabular}{|c|c|c|c|c|c|c|}
\hline \multirow[b]{2}{*}{ Eixos temáticos } & \multicolumn{6}{|c|}{ Etapas da educação básica } \\
\hline & $\begin{array}{c}\text { Educação } \\
\text { infantil }\end{array}$ & $\begin{array}{l}\text { Ensino fun- } \\
\text { damental }\end{array}$ & $\begin{array}{l}\text { Ensino fun- } \\
\text { damental e } \\
\text { médio }\end{array}$ & $\begin{array}{l}\text { Ensino } \\
\text { médio }\end{array}$ & $\begin{array}{c}\text { Ensino } \\
\text { médio (Pro- } \\
\text { fissionali- } \\
\text { zante) }\end{array}$ & Total \\
\hline $\begin{array}{l}\text { Aspectos teórico- } \\
\text { históricos sobre o } \\
\text { trabalho docente }\end{array}$ & 2 & 8 & 1 & 0 & 1 & 12 \\
\hline $\begin{array}{l}\text { Condições/relações de } \\
\text { trabalho docente }\end{array}$ & 0 & 16 & 3 & 3 & 3 & 25 \\
\hline Formação docente & 3 & 24 & 4 & 31 & 27 & 89 \\
\hline $\begin{array}{l}\text { Gênero e trabalho } \\
\text { docente }\end{array}$ & 3 & 13 & 0 & 1 & 2 & 19 \\
\hline $\begin{array}{l}\text { Identidade e trabalho } \\
\text { docente }\end{array}$ & 0 & 5 & 0 & 3 & 1 & 9 \\
\hline $\begin{array}{l}\text { Impacto das reformas } \\
\text { sobre o trabalho } \\
\text { docente }\end{array}$ & 1 & 22 & 3 & 3 & 0 & 29 \\
\hline $\begin{array}{l}\text { Mal-estar docente e } \\
\text { saúde do professor }\end{array}$ & 0 & 13 & 0 & 2 & 0 & 15 \\
\hline $\begin{array}{l}\text { Natureza e processo } \\
\text { de trabalho docente }\end{array}$ & 0 & 15 & 3 & 1 & 0 & 19 \\
\hline $\begin{array}{l}\text { Novas tecnologias e } \\
\text { trabalho docente }\end{array}$ & 1 & 2 & 2 & 0 & 0 & 5 \\
\hline Perfil de professores & 0 & 5 & 0 & 1 & 0 & 6 \\
\hline $\begin{array}{l}\text { Práticas educativas e } \\
\text { saberes docentes }\end{array}$ & 1 & 7 & 1 & 1 & 0 & 10 \\
\hline $\begin{array}{l}\text { Sindicalismo-resistên- } \\
\text { cia e trabalho docente }\end{array}$ & 0 & 1 & 2 & 0 & 1 & 4 \\
\hline $\begin{array}{l}\text { Representações, senti- } \\
\text { dos e significados }\end{array}$ & 1 & 14 & 0 & 4 & 5 & 24 \\
\hline Total & 12 & 145 & 19 & 50 & 40 & 266 \\
\hline
\end{tabular}

FONTE: Banco de dissertações e teses da Capes. 
As dissertações e as teses encontradas estão sendo desenvolvidas, em sua maioria, ou seja, 80,5\% (Gráfico 1) em cursos de pós-graduação em Educação, em suas diferentes áreas de concentração (política educacional, educação escolar, psicologia da educação, currículo, história da educação, sociologia da educação). Nas outras áreas do conhecimento, destacam-se os trabalhos realizados nos cursos de pós-graduação em ciências sociais (sociologia, antropologia e ciência política), que somam dez trabalhos: de psicologia, que aparece também com dez trabalhos, de história e da área de saúde, com 6 trabalhos cada uma delas (Gráfico 1).

GRÁFICO 1 - TESES E DISSERTAÇÕES SOBRE TRABALHO DOCENTE, POR ÁREA DE ORIGEM 1987-2007

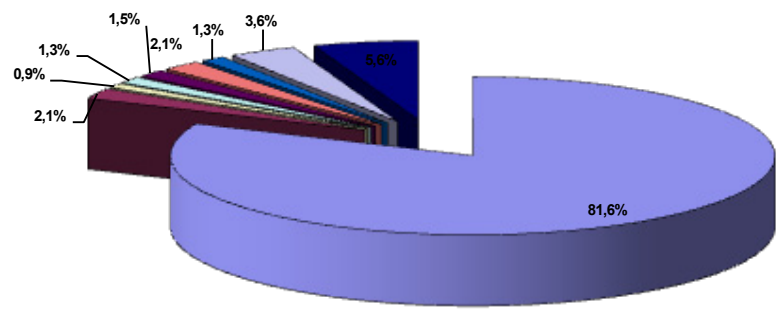

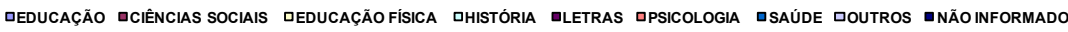

FONTE: Banco de dissertações e teses da Capes.

Quanto ao lócus de produção nesse campo de estudo, verificou-se que as dissertações e as teses encontradas foram desenvolvidas nas instituições públicas, situação que reitera as condições de produção científica no Brasil. Essas instituições aparecem com 355 trabalhos defendidos, o que corresponde a $76 \%$ do total, e as instituições privadas, que congregam 112 dissertações e teses (24\%). Conforme está indicando no Gráfico 2, entre as instituições públicas, as mais produtivas em dissertações e teses sobre trabalho docente são: Unesp (38), USP (35), UFMG (30); e Unicamp (25), que reúnem $27 \%$ do total dos trabalhos. Destacam-se ainda, entre as universidades públicas, a produção feita na UFRGS (19), UFSC (15), UFSCAR (15), UFRJ (14), UFBA (13), UFPE (13), UFC (11) e UNB (10). Nas instituições privadas, sobressai a elaboração da PUC/SP, que sozinha congrega 49 produções sobre o trabalho docente, ou seja, 10,5\% das dissertações e teses elaboradas (Gráfico 2). 
GRÁFICO 2 - DISSERTAÇÕES E TESES PRODUZIDAS POR INSTITUIÇÃO E POR PERÍODO HISTÓRICO (1997-2007 e 1987-1996)

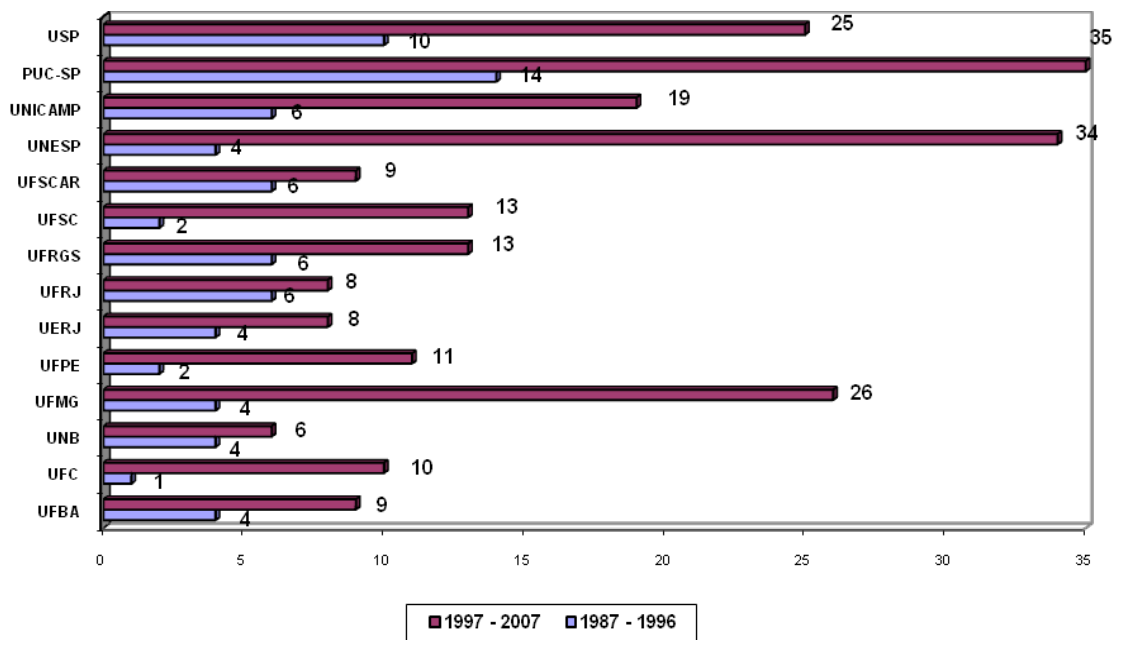

FONTE: Banco de dissertações e teses da Capes.

Verifica-se na Tabela 5 que a PUC/SP, que reuniu produção maior, tem, entre os seus 49 trabalhos, 19 catalogados no eixo temático "Formação Docente", o que corresponde a 39\% da sua produção. Essa instituição apresentou também um acúmulo de trabalhos nos eixos "Aspectos histórico/teóricos sobre o trabalho docente", com sete dissertações e teses (14\%), e também no eixo "Trabalho Docente: Representações, Sentidos e Significados", com sete elaborações (14\%). Também a Unesp apresentou o seu maior número de trabalhos no eixo "Formação Docente", com 12 dissertações e teses, ou seja, 32\% dos trabalhos. Em segundo lugar, aparece a produção no eixo "Impacto das Reformas sobre o Trabalho Docente", com seis trabalhos (16\%). Na USP, há uma distribuição mais equilibrada da produção entre os eixos temáticos e a maior concentração está no eixo "Formação Docente", com seis trabalhos (17\%); seguido do eixo "Impactos das Reformas sobre o Trabalho Docente" com cinco trabalhos (14\%). Na UFMG, a produção agrupa-se no eixo "Condições e Relações de Trabalho", com nove das 30 dissertações e teses produzidas, ou seja, 30\% dos trabalhos. Em seguida, aparece o eixo "Formação Docente" com 17\%, e ainda os eixos referentes ao "Mal-Estar Docente e Saúde do Professor" (13\%) e "Natureza e Processo de Trabalho", também com 13\% das produções (Tabela 5). 
TABELA 5 - DISSERTAÇÕES E TESES PRODUZIDAS SOBRE TRABALHO DOCENTE, POR INSTITUIÇÃO E EIXOS TEMÁTICOS - 1987-2007

\begin{tabular}{|c|c|c|c|c|c|c|c|c|c|}
\hline \multirow{2}{*}{ Eixos temáticos } & \multicolumn{9}{|c|}{ UNIVERSIDADES } \\
\hline & PUC-SP & UFMG & UFRGS & UFRJ & UFSC & UFSCAR & UNESP & UNICAMP & USP \\
\hline $\begin{array}{l}\text { Aspectos teórico- } \\
\text { históricos sobre o } \\
\text { trabalho docente }\end{array}$ & 7 & 2 & 1 & 0 & 1 & 0 & 4 & 2 & 2 \\
\hline $\begin{array}{l}\text { Condições/relações de } \\
\text { trabalho docente }\end{array}$ & 3 & 9 & 2 & 0 & 2 & 2 & 5 & 8 & 2 \\
\hline Formação docente & 19 & 5 & 3 & 2 & 5 & 8 & 12 & 8 & 6 \\
\hline $\begin{array}{l}\text { Gênero e trabalho } \\
\text { docente }\end{array}$ & 3 & 2 & 3 & 0 & 1 & 0 & 2 & 1 & 3 \\
\hline $\begin{array}{l}\text { Identidade e trabalho } \\
\text { docente }\end{array}$ & 2 & 0 & 1 & 3 & 0 & 0 & 0 & 0 & 4 \\
\hline $\begin{array}{l}\text { Impacto das reformas } \\
\text { sobre o trabalho } \\
\text { docente }\end{array}$ & 2 & 1 & 1 & 0 & 1 & 0 & 6 & 0 & 5 \\
\hline $\begin{array}{l}\text { Mal-estar docente e } \\
\text { saúde do professor }\end{array}$ & 0 & 4 & 1 & 1 & 2 & 1 & 1 & 1 & 0 \\
\hline $\begin{array}{l}\text { Natureza e processo } \\
\text { de trabalho docente }\end{array}$ & 2 & 4 & 3 & 1 & 1 & 0 & 4 & 1 & 4 \\
\hline $\begin{array}{l}\text { Novas tecnologias e } \\
\text { trabalho docente }\end{array}$ & 0 & 2 & 0 & 2 & 0 & 0 & 0 & 0 & 0 \\
\hline Perfil de professores & 2 & 0 & 0 & 2 & 1 & 1 & 0 & 0 & 2 \\
\hline $\begin{array}{l}\text { Práticas educativas e } \\
\text { saberes docentes }\end{array}$ & 1 & 0 & 0 & 1 & 0 & 2 & 3 & 1 & 1 \\
\hline $\begin{array}{l}\text { Sindicalismo-resistên- } \\
\text { cia e trabalho docente }\end{array}$ & 1 & 0 & 2 & 1 & 1 & 1 & 0 & 0 & 3 \\
\hline $\begin{array}{l}\text { Representações, senti- } \\
\text { dos e significados }\end{array}$ & 7 & 1 & 2 & 1 & 0 & 0 & 1 & 3 & 3 \\
\hline Total & 49 & 30 & 19 & 14 & 15 & 15 & 38 & 25 & 35 \\
\hline
\end{tabular}

FONTE: Banco de dissertações e teses da Capes.

O eixo temático que concentra o maior número de trabalhos, considerando a produção geral (Tabela 6), foi o de "Formação Docente", com 114 dissertações e teses, $68 \%$ de toda a produção. Em seguida, aparece o eixo "Condições e Relações de Trabalho", com 55 produções, ou seja, 12\% do total; e, em terceiro, o eixo "Impactos das Reformas Educacionais sobre o Trabalho Docente", com 51 produções $(11 \%)$. Se analisarmos pelos períodos históricos adotados para este estudo, verificamos que a produção de trabalhos relativos aos temas "Condições e Relações de Trabalho"; "Identidade e Trabalho Docente"; "Mal-Estar e Saúde Docente"; "Impactos da Reforma sobre o Trabalho Docente"; "Natureza e Processo de Trabalho Docente"; cresceu significativamente (Tabela 6). Ou seja, em todos esses eixos temáticos houve aumentos superiores a $80 \%$ 
na produção, destacando-se aquele relativo ao "Mal-Estar e Saúde Docente", sobre o qual não havia registro no banco de dissertações e teses da Capes, de nenhum trabalho no período de 1987 a 1996, e apareceram, no período seguinte, 1997-2007, 23 trabalhos. Na verdade, se analisarmos todos os eixos temáticos, no decorrer dos dois períodos históricos, verificamos que houve um crescimento de pelo menos $50 \%$ em todos eles, com exceção do eixo referente a "Gênero e Trabalho Docente", que registrou crescimento de $10 \%$.

TABELA 6 - TESES E DISSERTAÇÕES PRODUZIDAS SOBRE TRABALHO DOCENTE POR EIXOS-TEMÁTICOS - 1987-2007

\begin{tabular}{|c|c|c|c|c|c|}
\hline \multirow{3}{*}{ Eixos temáticos } & \multicolumn{4}{|c|}{ Período } & \multirow{3}{*}{ Total } \\
\hline & \multicolumn{2}{|c|}{$1987-1996$} & \multicolumn{2}{|c|}{ 1997-2007 } & \\
\hline & Quant. & $\%$ & Quant. & $\%$ & \\
\hline $\begin{array}{l}\text { Aspectos teórico-históricos sobre } \\
\text { o trabalho docente }\end{array}$ & 7 & 22,6 & 24 & 77,4 & 31 \\
\hline $\begin{array}{l}\text { Condições/relações de trabalho } \\
\text { docente }\end{array}$ & 10 & 18,2 & 45 & 81,8 & 55 \\
\hline Formação docente & 35 & 30,7 & 79 & 69,3 & 114 \\
\hline Gênero e trabalho docente & 18 & 45,0 & 22 & 55,0 & 40 \\
\hline Identidade e trabalho docente & 3 & 13,0 & 20 & 87,0 & 23 \\
\hline $\begin{array}{l}\text { Impacto das reformas sobre o } \\
\text { trabalho docente }\end{array}$ & 4 & 7,8 & 47 & 92,2 & 51 \\
\hline $\begin{array}{l}\text { Mal-estar docente e saúde do } \\
\text { professor }\end{array}$ & 0 & - & 23 & 100,0 & 23 \\
\hline $\begin{array}{l}\text { Natureza e processo de trabalho } \\
\text { docente }\end{array}$ & 5 & 15,6 & 27 & 84,4 & 32 \\
\hline $\begin{array}{l}\text { Novas tecnologias e trabalho } \\
\text { docente }\end{array}$ & 2 & 20,0 & 8 & 80,0 & 10 \\
\hline Perfil de professores & 2 & 20,0 & 8 & 80,0 & 10 \\
\hline $\begin{array}{l}\text { Práticas educativas e saberes } \\
\text { docentes }\end{array}$ & 5 & 33,3 & 10 & 66,7 & 15 \\
\hline $\begin{array}{l}\text { Sindicalismo-resistência e traba- } \\
\text { lho docente }\end{array}$ & 6 & 30,0 & 14 & 70,0 & 20 \\
\hline $\begin{array}{l}\text { Trabalho docente: representações, } \\
\text { sentidos e significados }\end{array}$ & 12 & 27,9 & 31 & 72,1 & 43 \\
\hline Total & 109 & 23,3 & 358 & 76,7 & 467 \\
\hline
\end{tabular}

FONTE: Banco de dissertações e teses da Capes.

Se considerarmos os dois períodos históricos demarcados na introdução deste artigo para análise dos trabalhos (1987-1996 e 1997-2007), verifica-se que a produção de teses e dissertações sobre o trabalho docente teve crescimento de $328 \%$ no período 1997-2007, em relação a 1987-2006, conforme indicado na Tabela 7. 
TABELA 7 - TESES E DISSERTAÇÕES PRODUZIDAS SOBRE TRABALHO DOCENTE POR NÍVEL - 1987-2007

\begin{tabular}{l|c|c|c|c|c}
\hline \multirow{2}{*}{ Período } & \multicolumn{4}{|c|}{ Nível } & \multirow{2}{*}{ Total } \\
\cline { 2 - 5 } & \multicolumn{2}{|c|}{ Doutorado } & \multicolumn{2}{c}{ Mestrado } & \\
\hline $1987-1996$ & Quant. & $\%$ & Quant. & $\%$ & \\
$1997-2007$ & 65 & 12,8 & 95 & 87,2 & 109 \\
Total & $\mathbf{7 9}$ & 18,2 & 293 & 81,8 & 358 \\
\hline
\end{tabular}

FONTE: Banco de dissertações e teses da Capes.

O aumento do interesse acerca desta temática, que reflete nas produções realizadas no período de 1987-2007, pode ser atribuído, conforme já indicado em outros estudos do tipo ${ }^{6}$ pelo impacto que as reformas educacionais têm na organização da escola, no trabalho docente e na própria divisão do trabalho na escola. A complexidade e a premência do trabalho docente na escola pública atual, a qualidade das escolas públicas confrontadas com o trabalho docente pelos resultados das avaliações nacionais e estaduais realizadas, a própria demanda social sobre essa temática, despertaram a necessidade de aprofundamento desse campo de investigação.

Verifica-se também, nesse período, a formação e a consolidação de grupos de investigação nessa área, inscritos no diretório de grupos de pesquisa do $\mathrm{CNPq}^{7}$, o surgimento de linhas específicas de pesquisa sobre o trabalho docente no interior dos programas de pós-graduação, com o objetivo de se aprofundar as análises sobre essa temática e fornecer subsídios para a construção de políticas públicas.

Outro aspecto que se pode especular para o aumento da produção sobre o trabalhão docente é a própria expansão e o fortalecimento dos programas de pós-graduação em educação, no período, que ampliaram suas vagas de mestrado e doutorado, criaram o nível de doutoramento, e o próprio surgimento de novos programas de pós-graduação no âmbito do setor público e do setor privado. Segundo Amaral (2009), de 1987 a 2007, houve um crescimento contínuo da pós-graduação como um todo, no Brasil, com a ampliação de cursos de mestrado e doutorado, o que vem se refletindo proporcionalmente no número de produções acadêmicas, como pode ser observado no aumento significativo dos artigos publicados em periódicos.

6 Ver Hipólito (1994); Oliveira (2003); Tumolo e Fontana (2008).

7 Consultar $<$ www.cnpq.br $>$. 


\section{Considerações finais}

O estudo quantitativo realizado mostra que o trabalho docente pode ser analisado sob diferentes aspectos (Tabela 6): gênero, identidade, perfil, representações, formação docente, práticas docentes, saberes docentes, condições e relações de trabalho, natureza e processo de trabalho, saúde e mal-estar docente, sindicalismo e impacto das novas tecnologias sobre o trabalho docente.

Os resultados apresentados (Tabela 6) indicam que no período de 19871997 as pesquisas realizadas sobre o trabalho docente, principalmente nos programas de pós-graduação em educação (mestrado e doutorado) nas instituições públicas e privadas se concentraram em temas relativos à formação docente e aos impactos das reformas educacionais sobre o trabalho docente, destacando-se aspectos como condições e relações de trabalho, natureza e processo de trabalho, representações sentidos e significados da profissão docente (Tabela 6). Nesse sentido, pode-se dizer que a produção acadêmica acompanha os acontecimentos políticos, econômicos e sociais do seu tempo. Ou seja, a pesquisa acadêmica colocou em foco as mudanças que estavam ocorrendo com o processo de reformas e novas regulações educacionais nos anos 1990 e seus impactos no interior da organização escolar e sobre o trabalho docente.

Concomitantemente à permanência de alguns temas em ambos os períodos estudados, observa-se o surgimento e o fortalecimento de estudos de novos temas como a "saúde e o mal-estar docente" (Tabela 6). Esse resultado vai de encontro aos estudos de Martinez (2003) que mostram que somente na década de 1980 é que os trabalhos sobre a saúde dos professores começam a se despontar, a partir de dados epidemiológicos psiquiátricos e estudos sobre o sofrimento psíquico causado pelo trabalho docente. Segundo essa autora, essas investigações vão incentivar outros campos de estudo como a sociologia e a psicologia do trabalho, que começam também dar a devida atenção a essa categoria de trabalhadores.

Este estudo inicial sobre as produções relativas ao trabalho docente pretendeu ser essencialmente descritivo, considerando que este é o primeiro passo em direção à análise qualitativa do que vem sendo produzido sobre essa temática. Outros passos são fundamentais para avançar no estudo, ou seja, identificar os trabalhos que estão efetivamente contribuindo para a construção do conhecimento na área, o que vai além do estudo dos resumos apresentados; comparar os resultados a que chegam as diferentes pesquisas que têm objetos de estudo comuns, apontando as abordagens teóricas utilizadas, tendências, resultados similares ou contraditórios. É fundamental, ainda, que este estudo se expanda para além das dissertações e teses produzidas na área e avance para a análise 
de artigos publicados em periódicos e livros, além de confrontar a produção acadêmica nacional sobre o trabalho docente com a produção internacional. É o que se pretende encaminhar!

\section{REFERÊNCIAS}

AMARAL, Lívio. Entrevista. Informe Escola Nacional de Saúde Pública Sérgio Arouca - ENSP. 1\%10/2009. Disponível em: <http://www.ensp.fiocruz.br/portal-ensp/ informe/ materia/index.php?matid=18514>. Acesso em: 8/11/2009.

ANDRÉ, Marli; SIMÕES, Regina; CARVALHO Janete; BRZEZINSKI, Iria. Estado da arte da formação de professores no Brasil. Educação e Sociedade, ano XX, n. 68, p. 301-320, dez. 1999.

BIRGIN, A. Novas regulações do trabalho docente: o caso da reforma argentina. Cadernos de Pesquisa, São Paulo, n. 111, p. 95-113, dez. 2000.

BREZEZINSKI, Iria. Trabalho docente, tecnologias e educação. Anais do IV Simpósio Trabalho e Educação, ago/2007. 1 CD-ROM.

BREZINSKI, Iria; GARRIDO, Elza. Estados da arte sobre formação de professores nos trabalhos apresentados no GT 8 da ANPED: 1990-1998. In: Anais da REUNIÃO ANUAL DA $22^{\mathrm{a}}$ ASSOCIAÇÃO NACIONAL DE PÓS-GRADUAÇÃO E PESQUISA EM EDUCAÇÃO - ANPED. Anais... Caxambu, MG, 1999. 1 CD-ROM.

DUARTE, Adriana; OLIVEIRA, Dalila A.; AUGUSTO, Maria Helena; MELO, Savana. Envolvimento docente na interpretação do seu trabalho: uma estratégia metodológica. Cadernos de Pesquisa, v. 38, n. 133, p. 221-236, jan./abr. 2008.

FERREIRA, Norma Sandra de A. Pesquisa em leitura: um estudo dos resumos de dissertações de mestrado e teses de doutorado defendidas no Brasil: de 1980 a 1995. Tese (Doutorado) - Faculdade de Educação da UNICAMP, Campinas, 1999.

FERREIRA, Norma Sandra A. As pesquisas denominadas "estado da arte". Educação e Sociedade, ano XXIII, n. 78, p. 257-272, ago. 2002.

HIPÓLITO, Álvaro L. M. Processo de trabalho docente: uma análise a partir das relações de classe e gênero. Dissertação (Mestrado em Educação) - Faculdade de Educação, Universidade Federal de Minas Gerais, Belo Horizonte, 1994. 
MARTINEZ, Deolídia. Estudos do trabalho docente. In: OLIVIERA, D. A. Reformas educacionais na América Latina e os trabalhadores docentes. Belo Horizonte: Autêntica, 2003. p. 75-86.

OLIVEIRA, Dalila A. As reformas educacionais e suas repercussões sobre o trabalho docente. In: OLIVEIRA, D. A. (Org.). Reformas educacionais na América Latina e os trabalhadores docentes. Belo Horizonte: Autêntica, 2003. p. 13-38.

ROMANOVISKI, Joana P.; ENS, Romilda T. As pesquisas denominadas do tipo "Estado da Arte" em educação. Diálogo Educacional, Curitiba, v. 6, n. 19, p. 37-50, set/dez. 2006.

SOARES, Magda B; MACIEL, Francisca. Alfabetização. Brasília-DF: MEC/INEP/ COMPED, 2000. 95p (Estado do Conhecimento, n. 1).

STEPHANOU, Maria. Jogo de memórias nas esquinas dos tempos: territórios e práticas da pesquisa (auto)biográfica na pós-graduação em Educação do Brasil. In: SOUZA, E. C.; PASSEGGI, M. C. (Org.). Pesquisa (Auto)Biográfica: cotidiano, imaginário e memória. Natal/RN: EDUFRN; São Paulo: Paulus, 2008. p. 19-53.

TUMOLO, Paulo Sérgio; FONTANA, Klalter Bez. Trabalho docente e capitalismo: um estudo crítico da produção acadêmica da década de 1990. Educação e Sociedade, v. 29 , n. 102 , p. 159-180, jan./abr. 2008.

Texto recebido em novembro de 2009.

Texto aprovado em maio de 2010. 